\title{
NiO Nano-Flower Sensitized by Perovskite as Photocathode for p-DSSC with Superior Hole Transfer Kinetics
}

\author{
Jie $Q u^{1, *}$, YurongRen ${ }^{l}$, Jia Cheng ${ }^{2}$, JianningDing ${ }^{1, *}$, NingyiYuan $^{l}$ \\ ${ }^{1}$ School of Materials Science and Engineering, Jiangsu Collaborative Innovation Center of \\ Photovoltaic Science and Engineering and Jiangsu Province Cultivation base for State Key Laboratory \\ of Photovoltaic Science and Technology, Changzhou University, Changzhou 213164, P. R. China \\ ${ }^{2}$ Hunan Hua Teng Pharmaceutical Co., Ltd, Changsha 410205, P. R. China \\ *E-mail: qujie1981@cczu.edu.cn; dingjn@cczu.edu.cn
}

doi: $10.20964 / 2016.09 .61$

Received: 24 June2016/ Accepted: 19 July 2016 / Published: 7 August 2016

$\mathrm{NiO}$ nano-flower, $\mathrm{NiO}$ slice-cluster and $\mathrm{NiO}$ nanoparticles have been synthesized by a facile method. The structure and morphology of the prepared samples were characterized by X-ray diffraction (XRD) and transmission electron microscopy (TEM). The as prepared samples are used as photocathode of p-DSSC. Current-voltage (I-V) curve shows that NiO nano-flower owns the highest $\mathrm{J}_{\mathrm{sc}}$ of $10 \mathrm{~mA} \mathrm{~cm}^{-2}$ and its efficiency can reach up to $0.84 \%$. The UV-vis diffused reflectance spectra indicate that $\mathrm{NiO}$ nano-flower shows strong light scatting and diffuse reflection to enhace light harvesting. Electrochemical impendence spectroscopy (EIS), intensity-modulated photocurrent spectroscopy (IMPS), and intensity-modulated voltage spectroscopy (IMVS) further demonstrate that $\mathrm{NiO}$ nano-flower provides fast hole transfer, long electron life time and improved charge collection efficiency with suppressed recombination.

Keywords: p-type dye sensitized solar cell; photocathode; $\mathrm{NiO}$ nano-flower;perovskite; hole transfer

\section{FULL TEXT}

(C) 2016 The Authors. Published by ESG (www.electrochemsci.org). This article is an open access article distributed under the terms and conditions of the Creative Commons Attribution license (http://creativecommons.org/licenses/by/4.0/). 